\title{
LA ATENCIÓN AL PLURALISMO EN LA TELEVISIÓN PÚBLICA ESPAÑOLA. UNA FUNCIÓN DE SERVICIO PÚBLICO
}

\section{PLURALISM ATENTION IN SPANISH PUBLIC TELEVISION. A PUBLIC SERVICE FUNCTION}

\author{
AUTOR/ES \\ Luis Javier Martínez-Rolán: Universidade de Santiago de Compostela. Santiago de \\ Compostela (España) \\ xabier.rolan@gmail.com
}

M $^{a}$ Teresa Piñeiro-Otero: Universidade de Vigo. Pontevedra (España)

Teresa.pineiro@gmail.com

\section{CURRÍCULUM VITAE}

Luis Javier Martínez Rolán es Licenciado en Comunicación Audiovisual por la Universidade de Vigo. Universidad donde adquirió el grado de licenciado con la tesis Ética y telebasura: relaciones entre Estado, televisión y ciudadanía. En la actualidad es alumno del programa de doctorado Procesos políticos contemporáneos del Departamento de Ciencias Políticas y de la Administración de la Universidade de Santiago de Compostela.

M Teresa Piñeiro Otero es Licenciada con grado en Publicidad y Relaciones Públicas por la Universidad de Vigo. Universidad en la que adquirió el Diploma de Estudios Avanzados en el programa de doctorado Comunicación, Publicidad, Relaciones Públicas y Protocolo. Ha enfocado su investigación al medio radiofónico tanto desde la perspectiva de la publicidad, ámbito en el que desarrolla su tesis de doctorado, como de las nuevas manifestaciones del medio sonoro. 


\title{
RESUMEN
}

La noción de la televisión como servicio público en la actualidad, se encuentra desdibujada dentro de la encarnizada lucha que mantienen las cadenas televisivas por la audiencia. Esta función de servicio público resulta esencial para garantizar una mayor calidad y pluralismo en los contenidos televisivos, sobre todo desde la perspectiva de la televisión como transmisor de valores e identidades. Un ejemplo de esta pluralismo se puede extraer de la programación de carácter religioso que posee la televisión pública española; unos espacios que han dotado de voz a algunas de las confesiones minoritarias de la España multicultural del S.XXI).

\section{PALABRAS CLAVE}

Televisión - Servicio Público - Pluralismo - Minorías - Identidades

\begin{abstract}
Nowadays, the notion of television as a public service is in a cruel fight between tv channels for getting audience. This function of public service is essential to guarantee a great quality and plurality in television contents, especially from the perspective of the television as values and identities transmisor. Religious programms in Spanish public television are example of this plurality; spaces that had fulfilled of voice on $\mathrm{tv}$ with some religious minorities.
\end{abstract}

\section{KEY WORDS}

Television - Public Services - Pluralism - Minorities - Identities 


\section{ÍNDICE}

1. Introducción

2. Aproximación al concepto de televisión como servicio público.

3. Servicio público y calidad televisiva.

4. El lugar de las minorías en el servicio público de la televisión.

5. Un ejemplo de pluralismo: la programación religiosa de tve.

6. Bibliografía.

\section{Introducción.}

Los contenidos televisivos desarrollan un papel determinante en la construcción de la realidad social y en los roles desempeñados por los individuos dentro de ella. Los mensajes televisivos van a afectar, de un modo más o menos consciente, la concepción que los individuos tienen del mundo que lo rodea.

En un contexto como el actual, caracterizado por un predominio de mensajes audiovisuales, la televisión ha adquirido el rango de agente socializador a la altura de instituciones clásicas como la familia, la escuela o el grupo de pares. La injerencia del medio televisivo en el proceso de formación de la persona puede entenderse, siguiendo a Hyde (1995), dentro de un proceso de transmisión de las expectativas de una sociedad con respecto a la conducta de un determinado colectivo. 
El proceso de mediación en el que se inscribe la televisión exige un compromiso con la calidad y pluralidad de contenidos; un desafío que se ha potenciado con la liberalización del sector audiovisual -a partir de los años 80- y el incremento de la oferta televisiva.

No obstante, la aparición de nuevos canales de televisión lejos de repercutir en la calidad y pluralismo del producto televisivo, supuso el inicio de una tendencia a la deformación de sus contenidos que ha dado lugar a una crisis en la concepción de la televisión como servicio público.

Hoy el sector audiovisual europeo se encuentra en pleno proceso de redefinición, del que es partícipe la televisión española, que ha rescatado el antiguo debate en torno al papel del Estado en la titularidad y gestión de la radiotelevisión.

Asimismo, los cambios vividos por el panorama audiovisual en los últimos años como la digitalización, la convergencia tecnológica, la caída de los monopolios público, la multiplicación de la oferta de canales, el inicio y estancamiento el proceso de liberalización, la crisis del modelo tradicional de financiación y de gestión o la concentración de las empresas audiovisuales -entre otros- han puesto de relieve la insuficiencia de la legislación actual (Muñoz Saldaña, 2006).

La definición de la televisión como servicio público ha dado origen a un intenso debate de ámbito internacional, que se ha visto reflejado en la jurisprudencia española y europea.

Tal como afirma Bustamante (2006), el modelo social europeo ha configurado 
históricamente el servicio público de la radiotelevisión como pieza clave dentro del espacio público de las sociedades democráticas. En el caso concreto de la televisión española, el hecho de que su nacimiento estuviese vinculado a un régimen autoritario en lugar de al Estado, favoreció que sus fundamentos careciesen de una concepción de servicio público propiamente dicha (Bustamante, 2006).

A pesar de esta tara en la consolidación del servicio público de la televisión española, dentro del ordenamiento jurídico español se pueden rastrear diversos antecedentes que reservan al sector público los servicios de la radiodifusión.

Autores como Herreros López (2004) sitúan el punto de partida de la regulación del servicio público de la radiodifusión en España en la Ley del 26 de octubre de 1907. Esta Ley reservó para el Estado, por vez primera, el “establecimiento y explotación de todos los sistemas y aparatos aplicables a la llamada 'telegrafía hertziana, telegrafía eléctrica, radiotelegrafía' y demás procedimientos similares ya inventados o que puedan inventarse en el porvenir".

La reserva de este servicio para el Estado se manifiesta con mayor claridad en normas posteriores como en el Real Decreto de 27 de febrero de 1923, cuyo texto establecía que todas las estaciones radioeléctricas constituyen un monopolio del Estado, o la Real Orden de 7 de enero de 1930, por la que se declaró el servicio público de radiodifusión.

No sería hasta 1934, con la aprobación de la Ley de Radiocomunicación y Radiodifusión de 26 de junio, cuando se extendió la declaración de servicio público a la radiodifusión de imágenes. Esta Ley, que declaraba los servicios de radiodifusión como "función esencial y privativa del Estado" (Beneyto, 1961), continuó en vigor una vez finalizado 
el Franquismo.

De hecho, el posterior Decreto, del 14 de noviembre de 1952, actualiza alguna de las disposiciones de la Ley del 26 de junio de 1934, al tiempo que reconoce su vigencia.

“La misma Radiodifusión, aunque estimada propia del Estado, era explotada por concesionarias que estaban obligadas a mantener un cierto pluralismo, dejando espacios o tribunas diariamente a los partidos politicos y a las confesiones religiosas" (Beneyto, 1979).

El 28 de octubre de 1956, dos décadas después de la inclusión de la radiodifusión de imágenes en el servicio público, tuvo lugar la primera emisión de Televisión Española (en adelante TVE). TVE nació como un organismo gubernamental "sin personalidad jurídica propia alguna y sujeta al derecho administrativo", vinculada al Ministerio de Información y Turismo (Bustamante 2006).

Con la aprobación de la Ley de Prensa de 1966, ley que suprimió la censura previa aún manteniendo férreos controles sobre lo publicado, se perpetuó la idea de los medios de comunicación como un servicio público a disposición del régimen a pesar de que, siguiendo a Baget (2001)

“En TVE esta reforma no se notó en absoluto pero en cambio la apertura se manifestó en su presencia en los festivales y mercados internacionales de televisión, con la producción de programas especiales que daban una imagen de la realidad social de España muy diferente a la verdadera, y en especial por el rápido avance de sus infraestructuras de producción".

En lo que respecta a los documentos legales más reciente sobre el servicio público 
televisivo, resulta destacable el Estatuto de Radio Televisión Española de 1980. Este documento declaró a la televisión servicio público especial, y su contribución de titularidad estatal. Una declaración que ha estado presente de una forma más o menos explícita en toda la legislación española posterior, con la excepción de la Ley de Telecomunicaciones por satélite (Ley 31/1987, 18 de diciembre).

El Estatuto de Radio y Televisión se mantuvo vigente hasta la aprobación de la Ley 17/2006, de 5 de junio, de la radio y la televisión de titularidad estatal; Ley que configura este servicio público como un servicio esencial para la vida democrática destinado a garantizar su independencia, neutralidad y objetividad en busca del cumplimiento de su tarea de servicio público con eficacia y calidad.

Esta breve revisión normativa ha permitido poner de relieve que la consideración de la televisión como servicio público, no resulta una cuestión novedosa dentro del ordenamiento jurídico español, a pesar de que las particulares características de este servicio han dificultado su acotación y definición.

\section{Aproximación al concepto de televisión como servicio público}

Llevar a cabo una aproximación a la concepción de la televisión como servicio público resulta una tarea compleja, no exenta de controversia, dado lo impreciso de su definición. Las particulares características del medio televisivo, además de su relevante papel como agente socializador, ha llevado a su determinación como servicio público en múltiples países y -en consecuencia- a la aprobación de un reglamento específico. 
Desde una perspectiva muy básica, hablar del servicio público de la televisión implica referirse al Estado como propietario del espectro de radiofrecuencias y, por tanto, de su papel en la gestión de las licencias de emisión así como en la regularización de los criterios de obligado cumplimiento para los operadores televisivos a quiénes se las conceden. No obstante, la concepción de servicio público va más allá de la previsión de la titularidad del servicio de radiodifusión al Estado.

Corral (2005) puso de manifiesto que la complejidad en la definición del servicio público se hizo patente desde el momento en el que se comenzó a valorar la ruptura del monopolio de RTVE

“(...) La falta de una definición de servicio público de la televisión, supuso, en el momento de la apertura del monopolio, el planteamiento de una serie de problemas diversos. La mayoría de ellos derivan de la orientación comercial que, paulatinamente, ha ido adoptando la televisión pública, y del hecho de que su financiación no se haya limitado a producciones de servicio público".

Asimismo la desregularización vivida por el sector televisivo en el contexto español, sumada a determinadas imposiciones de carácter económico, ha propiciado que la noción de servicio público acabase desdibujada.

En términos generales se puede definir servicio público como aquella actividad técnica cuya finalidad es satisfacer una necesidad colectiva, desarrollada por el Estado o -de modo excepcional- por los particulares, que se encuentra bajo un régimen jurídico especial con la finalidad de asegurar su menor coste, eficiencia, continuidad y eficacia (Serra, 1983). 
Siguiendo a Gorostiaga (1982), servicio público es toda

“(...) aquella actividad del Estado, o de otra Administración pública, de prestación positiva, con la cual, mediante un procedimiento de Derecho público, se asegura la ejecución regular y continua, por organización pública o por delegación, de un servicio técnico indispensable para la vida social".

A pesar de que, siguiendo a Rodríguez García (1998), esta definición puede prestarse a confusión debido a la vinculación establecida entre propiedad, gestión y dirección, lo cierto es que Gorostiaga ofrece una serie de claves en torno al concepto de servicio público que se tratarán a continuación.

El servicio público:

- Se refiere a una actividad estatal, cuya titularidad asume el Estado. En el desempeño de esta titularidad, es el Estado quien debe velar por la calidad de los servicios televisivos.

- Se trata de una actividad destinada al público, es decir, que resulta útil a la ciudadanía. En su origen, la concepción del servicio público se entiende como una actividad basada en planteamientos utilitaristas, dirigidos a satisfacer una necesidad existente en la sociedad. Estos planteamientos están vinculados a la maximización del bienestar entre la mayoría de la población, a la que el servicio público de televisión satisface en el ámbito de las necesidades de comunicación social e interpersonal. La maximización del bienestar puede entenderse desde el punto de vista del máximo pluralismo sobre el que se adquiere especial relevancia el principio de participación; principio que en la práctica está limitado por la no igualdad de expresión: sólo unos pocos poseen los medios y tienen acceso a ellos. En este caso, siguiendo a Núñez Ladevéce y a Vázquez Barrio (2008), “Minorías son las que seleccionan los medios para 
influir en la opinión de muchos; y Mayorías quienes quedan fuera de los procesos de selección de los medios de comunicación social".

- Es una actividad necesaria, imprescindible para la vida social y el desarrollo de la ciudadanía. En relación con la característica anterior, el concepto de servicio público busca dar respuesta a una necesidad social, que afecta a la mayor parte de la población, y que se encuentra reconocida previamente por el Estado.

- Resulta una actividad cuya gestión no supone el ejercicio de poderes soberanos. Por tanto, hablar de servicio público es hacerlo de una actividad que se presenta como independiente, no subordinada a ningún tipo de poder fáctico, cuyos objetivos están encaminados a favorecer la cohesión social y ser de utilidad a la ciudadanía.

Desde la perspectiva de una actividad de utilidad para la ciudadanía, Rodríguez García (1998) ha definido el servicio público como una técnica jurídicoadministrativa que implica una mejor consecución de la protección y la garantía del pluralismo dentro de la sociedad, además de una serie de condiciones para que la libertad y la igualdad de oportunidades sean reales y efectivas.

En este sentido, la televisión debe asumir el reto de conjugar el ejercicio de las libertades individuales fundamentales con aquellas cuestiones de interés general, el respeto a la libertad y el derecho a la información (bien sea activo, bien pasivo) en busca del tan deseado equilibrio.

La noción de la televisión como servicio público ha desencadenado un intenso debate dentro y fuera de España. En Gran Bretaña, además de la ya célebre máxima de "informar, educar y entretener", el servicio público se vincula a los conceptos de 
universalidad y responsabilidad.

Si se parte del concepto de universalidad como la necesidad de llegar a todos los territorios y a una gran variedad de audiencias, la televisión en su función de servicio público debe promover unos contenidos adaptados -en la medida de lo posible- a los gustos e intereses de los diferentes públicos. La responsabilidad, por su parte, requiere que la televisión se preocupe por la información y la educación de la audiencia, no sólo de su entretenimiento.

Volviendo a la definición de Gorostiaga, en concreto a la parte que reza "cuya gestión no supone el ejercicio de poderes soberanos", otra de las características vinculadas a la concepción de servicio público es el de la independencia. La televisión debe de estar formal y realmente separada de la política, alejada de cualquier tipo de dominios internos de intereses particulares, al margen del grupo del que provengan.

Este camino hacia la constitución real del servicio público, a priori más complejo, exige a los operadores de televisión una mayor creatividad, nuevas alternativas, un alto nivel de calidad y el fomento del consenso cultural. Esta exigencia resulta de especial relevancia en lo que se refiere a las emisoras de titularidad pública cuyo cometido presenta una serie de compromisos adicionales con la ciudadanía, preservados por sus órganos de control y tutela.

Para Muñoz Machado (1998) la noción de servicio público de la televisión parte esencialmente de una limitación a la libertad de comunicación, que consiste en el establecimiento de obligaciones a los operadores de televisión públicos y privados a efectos de salvaguardar algunos derechos y libertades constitucionales y preservar 
una serie de valores educativos y culturales.

Frente otro tipo de servicios públicos, como la educación y la sanidad, la televisión merece especial atención si se parte del hecho de que puede llegar a convertirse en un auténtico aparato ideológico del Estado; en un insuperable transmisor del way of life de la población de un país. Más concretamente, Jiménez Filpo (2005) ha puesto de relevancia el papel de la televisión en la

"configuración de estados de ánimo colectivos, en la generación de la opinión pública, en la reproducción cultural, en la defensa de las identidades culturales y nacionales y en la creación del consenso. Una auténtica columna vertebral sobre la que se sostiene el Estado moderno".

Un papel que adquiere mayor relevancia si se atiende al hecho de que, como reza la Comunicación de la Comisión Europea de 17 de octubre de 2001 sobre la aplicación de las normas en materia de ayudas estatales a los servicios públicos de radiodifusión, no existe ningún otro servicio que de forma simultánea "tenga un acceso tan amplio a la población, proporcione tal cantidad de informaciones y contenidos y, de este modo, transmita las opiniones individuales y la opinión pública e influya tanto en las mismas".

En definitiva, el medio televisivo funciona como soporte de una realidad social en la que se incluye el patrimonio cultural de un país a través de la cuál, se transmite la identidad; una actuación que exige velar por la preservación de este servicio público. 


\section{Servicio público y calidad televisiva.}

En el contexto de la televisión española, el concepto de programación de servicio público adquiere particular relevancia en lo que se refiere a aquellas emisoras de titularidad pública. Una concepción de servicio público que se ha visto diluida por la sujeción de las cadenas televisivas públicas y privadas a la tiranía de las audiencias (entendidas como indicador del mercado).

Tal como señalan Popper y Condry (1999) en la consecución de los "preciados" índices de audiencia, las televisiones no han dudado en acudir a tres ingredientes fundamentales: violencia, sexo y sensacionalismo. Esta sumisión a los imperativos de las audiencias y su tiranía diaria ha provocado una nivelación de los contenidos por lo bajo, que ha tenido consecuencia directa en los programas destinados a determinados públicos como el infantil, el juvenil y a aquellos colectivos más vulnerables.

Cada vez más, la oferta de televisión pública tiende a parecerse a la de la televisión privada; una tendencia que no sólo se observa en la homogeneización de contenidos sino que -incluso- ha supuesto una degradación de la exigencia cultural (Gubern, 2006). Tal como subraya Bordieu (1998) la preocupación por divertir a la audiencia a cualquier precio ha propiciado que determinados contenidos como los informativos o políticos hayan quedado excluidos de los horarios de mayor audiencia y que continuamente sean transformados en un espectáculo más atractivo para sus públicos.

De este modo se puede constatar la existencia de una participación bidireccional del público en los contenidos televisivos: por un lado el público condiciona la oferta de 
estos contenidos; por otro, es la televisión la que determina la programación que consume el espectador al no contar éste con alternativas diferentes. Una circunstancia que hace preciso abordar el concepto de calidad televisiva.

Como norma general, el rasgo definitorio del servicio público debe ser la calidad; calidad entendida como el desarrollo de un tratamiento informativo orientado por criterios profesionales que den apoyo al pluralismo político, social y cultural, y establezcan una serie de mecanismos que garanticen la independencia (Moragas y Prado, 2001).

Pero también es calidad la preservación de parcelas informativas, más allá de la espectacularización televisiva, en busca de favorecer la formación de un criterio sobre los temas de relevancia para la sociedad; la elaboración programas de análisis sobre temas complejos para facilitar su comprensión a la población, o nuevas formas de tratamiento informativo que consigan la atención del público sin desvirtuar los contenidos; la oferta de contenidos de interés para determinados sectores o colectivos de la población como los programas sobre minorías; o la creación de las condiciones que favorezcan la creatividad, la programación de propuestas innovadoras en franjas de máxima audiencia y su mantenimiento el tiempo preciso para la adaptación de la audiencia (Moragas y Prado, 2001).

En cualquier caso, la calidad emerge como una exigencia fundamental del servicio público televisivo. Dicha exigencia se hace especialmente patente en las cadenas de titularidad pública en las que, siguiendo a Moragas y Prado (2001), coexisten dos concepciones diferentes de televisión: la que ejerce un rol subsidiario con una oferta de contenidos que, dado su público minoritario y elevado coste, sería impensable en las cadenas privadas; y la que detenta un rol protagonista con una programación 
destinada al público general que garantiza una cuota de penetración amplia, permitiéndole cumplir una serie de objetivos como servicio público.

Dos funciones complementarias y perfectamente integradas en la televisión pública europea que se han materializado, dentro de los diversos sistemas estatales, en sendas cadenas generalistas: la primera, más competitiva, cuenta con una programación destinada a un público más amplio (es el caso de RAI1 en Italia, France 2 en Francia, RTP1 en Portugal o TVE1 en España); la segunda, que asume las exigencias de servicio público menos lucrativas, lo que supone una dosis más alta de riesgo en cuanto a índices de audiencia (por ejemplo RAI2, France 3, RTP2 o La2).

\section{El lugar de las minorías en el servicio público de la televisión.}

A partir de la aproximación llevada a cabo en torno al concepto de servicio público se ha podido establecer la implicación de la televisión en la transmisión de la cultura e identidad de un país o de una región concreta. En este sentido, autores como Salcedo Megales (2000) defienden la obligación del Estado de apoyar aquella organización social que promueva identidades personales valiosas. Una postura que ha suscitado una intensa polémica entre los sectores más liberales, quienes la tachan de elitista, por pretender ofrecer una televisión de minorías.

No obstante, si la calidad televisiva está relacionada con concepto de minorías, el papel del Estado como defensor de esta minoría elitista se reafirma y, con ella, la protección de identidades culturales valiosas.

La Ley 17/2006, de 5 de junio, de la radio y la televisión de titularidad estatal, en su artículo 
2 señala que

"El servicio público de radio y televisión de titularidad del Estado es un servicio esencial para la comunidad y la cohesión de las sociedades democráticas que tiene por objeto la producción, edición y difusión de un conjunto de canales de radio y televisión con programaciones diversas y equilibradas para todo tipo de público, cubriendo todos los géneros y destinadas a satisfacer necesidades de información, cultura, educación y entretenimiento de la sociedad española; difundir su identidad y diversidad culturales; impulsar la sociedad de la información; promover el pluralismo, la participación y los demás valores constitucionales, garantizando el acceso de los grupos sociales y políticos significativos".

Posteriormente, en su artículo 3 atribuye a la Corporación de Radio y Televisión Española la gestión del servicio público de la televisión, en función de la cual deberá promover, entre otros, el conocimiento y difusión de los principios constitucionales y los valores cívicos; garantizar la información objetiva, veraz y plural; facilitar el debate y la libertad de expresión; promover la participación democrática; promover la cohesión territorial, la pluralidad y la diversidad lingüística y cultural o apoyar la integración social de las minorías y atender a grupos sociales con necesidades específicas.

Dentro de la extensa enumeración que el artículo tercero de la Ley 17/2006 desarrolla sobre las cuestiones que debe tener en cuenta la Corporación de Radio y Televisión Española como gestora del servicio público, se ha prestado especial interés a aquellas relativas al pluralismo, el apoyo a la diversidad y la integración social de las minorías. La selección de estas cuestiones no resulta aleatoria, sino que se corresponden con el objeto de reflexión del presente artículo: la atención al pluralismo por parte de Televisión Española (TVE). Una atención que se ha reflejado en una programación que ha incorporado con relativo éxito contenidos vinculados a 
determinadas minorías, como por ejemplo las de carácter religioso.

En la actualidad, como subraya Calhoun (1994), no se conoce ningún caso de sociedad o cultura en la que, de algún modo, no se realice alguna distinción entre un "yo" y un "otro", un "nosotros" y un "ellos". Incluso se podría dar un paso más y afirmar que la creciente fragmentación existente en la sociedad globalizada, no hace más que reforzar estos conceptos.

Sin embargo, es frecuente que el tratamiento diferencial que existe entre grupos sociales mayoritarios, o mayorías, y grupos sociales minoritarios, o minorías, entrañe un principio de discriminación. Esta discriminación del exogrupo ("ellos") por el endogrupo ("nosotros") está cimentada sobre una desigualdad de poder; la mayor influencia de los unos frente a los otros (sin que necesariamente se tenga que vincular al grupo poderoso con el endogrupo y viceversa).

Sociológicamente el concepto de minoría se presenta íntimamente ligado al de identidad; un concepto cuya acotación entraña complejidad debido a su alto grado de polisemia. Hablar de identidad es hacerlo de una serie de características y rasgos propios que suponen la principal fuente de sentido entre individuos o colectividades (Morales, 1969) y que constituyen una poderosa herramienta conceptual, válida para el estudio de la realidad social, debido al gran interés sociológico que presenta su análisis.

Como elemento implicado en la conformación de la realidad social se puede considerar a la identidad como un concepto construido por un individuo o por una comunidad, de modo que su configuración está intrínsecamente unida a los conceptos, valores o percepciones que comparta el grupo mayoritario (o minoritario) 
de la población.

En este proceso de construcción de identidades intervienen múltiples aspectos, como la experiencia más inmediata, interacciones de la vida cotidiana, diferentes procesos sociales, etc. todos conectados, interrelacionados e inter-influyentes. La identidad se convierte así en el "resultado de un proceso tanto micro como macrosocial, en el que existe una relación dialéctica entre ambos niveles, y en el que la Identidad del Yo es la manera en que nosotros mismos nos percibimos de una manera refleja en función de nuestra biografía" (Giddens, 1995). El Yo es el resultado de conjugar las percepciones propias de los individuos, su percepción por parte de los demás y aquello que el individuo piensa que consideran los demás. Esto es: una identidad se construye no sólo con sus auto-ideas, sino con las ideas que recibe de los demás sobre ese "yo".

Como constructo, la identidad no es inmutable sino que se presenta permeable a influencias del exterior, como los medios de comunicación y, dado su mayor consumo y penetración, la televisión. La construcción de realidades sociales, identidades y minorías no resulta tarea sencilla sino que está sujeta a miles de interacciones.

El concepto de minoría cobra especial relevancia en el ámbito de las sociedades actuales cuya integración dentro del proceso de globalización, junto la profusión de movimientos migratorios, ha propiciado el salto de las sociedades monoculturales a las multiculturales. Países como España, que durante décadas constituyó un punto de partida de múltiples flujos migratorios, se han tenido que moldear a su nuevo papel de lugar de destino y/o comunidad de acogida. 
Dentro de este proceso de adaptación a la nueva realidad social, con la incorporación de nuevos colectivos étnicos, culturales y religiosos, adquiere un especial papel la función de servicio público de la televisión. Un servicio público que aboga por el pluralismo, con la intención de dar respuesta a las necesidades que presentan estos nuevos ciudadanos y fomentar la cohesión social.

La televisión y, en general, todos los medios de comunicación, se configuran como unas de las herramientas más importantes con las que cuenta el Estado para afrontar esta nueva realidad social. Como servicio público, la televisión detenta la responsabilidad de formar opiniones y modelar actitudes, al tiempo que defender valores cívicos como la tolerancia, la igualdad o la convivencia pacífica.

El medio televisivo desarrolla un papel activo en la creación y difusión de representaciones sociales sobre las minorías y determinados grupos étnicos, no en vano, para comprender los procesos de normalización del multiculturalismo resulta vital conocer el tipo de contribución y el grado de implicación de los media (Greenberg, Mastro y Brand, 2002).

Por esta razón, desde comienzo de la década de los noventa, la protección del pluralismo en los medios de comunicación ha sido una cuestión de interés en el ámbito comunitario. En efecto, la Unión Europea tiene entre sus cometidos la defensa del pluralismo mediático como pilar fundamental sobre el que se sustentan el derecho a la información y a la libertad de expresión. Derecho recogido en el Artículo 11 de la Carta de los Derechos Fundamentales de la Unión Europea (2000).

El pluralismo en la televisión puede ser entendido desde múltiples perspectivas, como la diversidad en la propiedad de las cadenas, en las fuentes de información o 
en la oferta de contenidos. Estas perspectivas no son excluyentes; en efecto, la concentración de propiedad suele vincularse con la presencia de un discurso informativo sesgado que excluye de los medios e, inclusive, relega al ostracismo mediático a aquellos colectivos sociales no interesantes para la minoría que gestiona los medios.

Es en este contexto donde adquiere relevancia el principio de participación, principio que en la práctica está limitado por la no igualdad de expresión: sólo unos pocos poseen los medios y tienen acceso a ellos.

La influencia de la televisión en la construcción de la ciudadanía fue establecida por Origlio (2008) atendiendo a dos ámbitos:

Por una parte la televisión favorece la generación de una serie de contenidos compartidos por un grupo social, que constituyen los denominados por Jackobson (1999) como common stock of knowledge, un base común que va a influir en el proceso de socialización del individuo. A su vez, la televisión como instrumento de representación de la realidad, detenta un papel importante como generadora de imágenes comunes, las pictures in the mind lippmianas, en torno la realidad sociocultural de un determinado país.

Por otra, y en relación con el ámbito anterior, la televisión es capaz de configurar una serie de imaginarios colectivos; imaginarios que presentan repercusión directa en la concepción de las minorías de un país. "La capacidad representativa de la televisión repercute de manera aún más directa en la condición de las minorías en un país, contribuyendo a la construcción de una idea de nación en la cual se le asigna a cada actor social lugares específicos en el mundo mediático, suponiendo su equivalencia 
al mundo real." (Origlio, 2008),

El hecho de analizar "la situación de los medios de comunicación masivos en relación a la diversidad cultural puede resultar extremadamente esclarecedora de la manera en la cual una sociedad se percibe a si misma y se quiere estructurar" (Origlio, 2008). O, como sostiene Chomsky (1994). los media se constituyen como creadores de consenso, desempeñando el papel de sustentadores del orden preestablecido, por lo que se convierten en instrumentos idóneos para los poderes políticos y económicos. En este caso, estas minorías selectas orteguianas se configuran como una mayoría simbólica dado que su utilización de la televisión les permite construir un discurso que va a influir en la propia realidad al momento de ser propuesto e incorporado por parte de las audiencias en su sentir común (Origlio, 2008).

En busca de garantizar este pluralismo o, manteniendo las características anteriormente mencionadas sobre el servicio público, esta universalidad exige la posibilidad de dar voz a todos los grupos sociales. Esta situación óptima, que implica la visibilización de las minorías, se corresponde con la concepción de una televisión generalista: generalista porque intenta ofrecer programas destinados a un público heterogéneo, al tiempo que cultiva todos los géneros e intenta satisfacer los intereses de los grupos minoritarios (de Moragas y Prado, 2001).

Diversidad cultural y pluralismo mediático son dos realidades indisociables que, como recoge la Declaración sobre la diversidad cultural (Consejo de Europa, 2000), se configuran junto a la libertad de los medios de comunicación como precondiciones básicas para el cambio cultural, el desarrollo de la democracia y la promoción de la diversidad. Unas funciones que fueron reconocidas por la Convención de la UNESCO sobre la Protección y promoción de la Diversidad en las Expresiones 
Culturales en 2005.

Si uno de los principales cometidos del servicio público de la televisión es el de garantizar la pluralidad, prestando una especial atención a aquellas minorías y/o colectivos especialmente sensibles, otro de ellos es la calidad de los contenidos. Una calidad que, en el caso concreto de pluralismo televisivo y diversidad, podría ser definida como "oferta de emisiones de interés sectorial como los programas sobre actividad parlamentaria, las campañas electorales, el debate, la educación, la cultura, el arte, el folklore o los programas sobre minorías" (Moragas y Prado, 2001). En este sentido, la calidad se refiere a una serie de contenidos que podrían englobarse dentro de la noción de servicio público, y entre los que se encontraría -entre otros- la programación asociada al pluralismo confesional.

Estos contenidos se incluyen, sin duda alguna, en la programación de servicio público que en la actualidad ofrece la televisión española que, dan respuesta a la posible demanda de determinadas colectividades religiosas sin perder de vista el contexto en el que se desarrolla.

\section{Un ejemplo de pluralismo: la programación religiosa de TVE.}

Televisión Española, en el ejercicio de su labor de servicio público cuenta entre sus contenidos con diversos programas enfocados en las diversas confesiones presentes en el Estado español.

El antecedente de estos programas se puede buscar en la retransmisión de la Misa dominical para ancianos y enfermos, que forma ya parte de la historia de la 
radiotelevisión española. En efecto, la retransmisión de dicha Eucaristía (como parte programa Pueblo de Dios) continúa estando presente en la programación religiosa, condicionando -de algún modo- el día y la hora de emisión de los restantes espacios.

Más allá de la retransmisión litúrgica, referirse a la programación de carácter religioso en la televisión actual hace precisa una reconceptualización del fenómeno que abarca realidades más amplias como cultura, tradición o historia.

Estos programas de contenido religioso se emiten en la segunda cadena de Televisión Española (La 2), cadena que asume el rol subsidiario del servicio público con contenidos que se rigen por el principio de universalidad $y$, por tanto, oferta contenidos para diversos colectivos como las comunidades religiosas.

La distribución de los espacios de carácter religioso en la programación de Televisión Española, así como el tiempo destinado semanalmente a cada una de las confesiones atiende a la relevancia de cada comunidad concreta dentro de la sociedad española. Una relevancia que puede ser entendida en términos de volumen de una determinada comunidad de fieles, lo que explica la mayoría de contenidos relacionados con el Catolicismo o la presencia de programas destinados al Islamismo o a la comunidad Evangélica. No obstante, esta relevancia atiende a otros criterios como el cultural; criterios que han llevado al Estado a suscribir convenios con las comunidades Evangélica, Israelita e Islámica (Leyes 24/1992, 25/1992 y 26/1992, respectivamente). Tres comunidades que, junto la Católica, cuentan con espacios monográficos dentro de la programación de carácter estable como Shalom o Islam Hoy. 
Con la conversión de España en un Estado multicultural se han ido incorporando otro tipo de programas de carácter cultural-religioso que se pueden denominar contendedores, dado que focalizan su atención en diversas realidades confesionales, diferentes semana tras semana. Este es el caso de Babel.

Así, pese al enorme peso con el que cuenta la programación para la confesión católica en la parrilla de TVE, existen múltiples espacios y microespacios (monográficos y contenedores) dedicados a diversos colectivos religiosos. Esta circunstancia ha llevado a considerarla un ejemplo de pluralismo -al menos en la forma- $y$, en consecuencia, como parte de la función de servicio público del medio.

\section{Conclusión.}

La crisis de la noción de servicio público en la televisión está provocada por un abuso gratuito del término, cuya complejidad lo hace difícilmente acotable. Esta situación ha provocado que referirse al servicio público de la televisión se haya convertido en una expresión meramente formal, en muchos casos sin reflejo en la programación.

El debate en torno a si la televisión pública debe estructurar sus contenidos para conseguir mayor audiencia y, por tanto, rentabilidad o si, por el contrario, debe dar respuesta a las demandas programáticas de las diferentes minorías, resulta fuera de lugar en el contexto digital. En efecto, siempre que se respeten los principios de calidad y pluralidad, la multiplicidad de cadenas permite la coordinación de esfuerzos (en uno u otro sentido) para la consecución de los objetivos de carácter empresarial sin por ello tener que sacrificar los cometidos del servicio público. 
La configuración del mercado televisivo actual permite prestar una especial atención a las diferentes minorías culturales, étnicas, religiosas, etc. construyendo y difundiendo contenidos adecuados a sus demandas. Unos contenidos que, debido a su discreta rentabilidad en audiencia, se incluyen en la parrilla de televisión de las televisiones públicas y que, en un futuro próximo, podrán alcanzar mayor proyección en algunos de los múltiples canales de la televisión digital.

En este sentido, la televisión española debe asumir el reto de adecuar su programación de servicio público a la realidad social de España. Concretamente, la televisión pública debe incorporar entre sus espacios de carácter religioso-cultural a las diferentes comunidades religiosas, especialmente a aquellas confesiones que, debido al constante incremento de sus fieles, se están convirtiendo en mayoría dentro de las minorías.

La transmutación del medio analógico al digital presenta grandes oportunidades para el desarrollo de una televisión de calidad, pero también supone nuevos riesgos. En este contexto, se hace preciso proteger la función de servicio público como una garantía más del engranaje democrático frente a aquellos contenidos televisivos cuya única finalidad es la económica.

\section{Bibliografía.}

BAGET, J.M. (2001): “El legado de la televisión franquista" en Revista Formats, n 3. Disponible en: http://www.iua.upf.es/formats/formats3/bag_e.htm (Consultado el 10/07/2007).

BENEYTO, J. (1961): Ordenamiento jurídico de la información. Instituto de Estudios 
Políticos. Madrid.

BENEYTO, J. (1979): “La política de comunicación en España durante el franquismo”, en Revista de estudios políticos, nº 11. Pág. 157-170.

BORDIEU, P. (1998). Sobre la televisión. Anagrama. Barcelona.

BUSTAMANTE, E. (2006): Radio y television en España: historia de una asignatura pendiente de la democracia. Gedisa. Barcelona.

CALHOUN, C. (1994): Social Theory and the Politics of Identity. Blackwell. Cambridge.

DE MORAGAS, M. y PRADO, E. (2001): “Repensar la televisión pública en elcontexto digital", en Portal de la Comunicación. Disponible en http://www.portalcomunicacion.com/both/opc/tvp.pdf (2/02/2008).

DEL CORRAL, J. (2005): “El futuro de las televisones públicas". J. F. GARCÍA CASANOVA y J. M. CASADO SALINAS (eds.), El servicio público de la televisión. Editorial Universidad de Granada. Granada.

GIDDENS, A. (1995): Modernidad e Identidad del Yo. Península. Barcelona.

GOROSTIAGA, E. (1982). El Estatuto de la Radio y la Televisión. Forja. Madrid.

JACOBSON, R. N. (1999): “Race, Ethnicity and Public Sphere”, en International Sociolgy, nº14 (3). Pág. 355-375.

JIMÉNEZ FILPO, A. (2005). "El servicio público de la televisión" en J. F. GARCÍA CASANOVA y J. M. CASADO SALINAS (eds.), El servicio público de la televisión. Editorial Universidad de Granada. Granada.

LIPPMANN, W. (2003): La opinión pública. Langre. Madrid.

MUÑOZ MACHADO, S. (1998): Servicio público y mercado. Civitas. Madrid. Vol III.

MUÑOZ SALDAÑA, A. (2006): "La televisión que queremos, una perspectiva jurídica". Disponible en: http://www.unizar.es/berlatre/documentos/LaTVquequeremos.pdf /(Consultado 
el 10/01/2008).

NÚÑEZ LADEVÉCE, L. y VÁZQUEZ BARRIO, T. (2008) “Los líderes de opinión”, en Mediaciones sociales, $\mathrm{n}^{\mathrm{o}} 2 . \quad$ Disponible en: http://www.ucm.es/info/mediars/MediacioneS2/Indice/NunezVazquez/(10/03/ 2008).

ORIGLIO, B. (2008): “Televisión y minorías: modelos para la construcción de una participación democrática en México". Disponible en: http://www.alaic.net/alaic30/ponencias/cartas/Com_popular/ponencias/GT15_1 6Origlio.pdf (10/03/2008).

RODRÍGUEZ GARCÍA, J.A. (1998): El control de los medios de comunicación: participación de los grupos ideológicos en el control de los medios de comunicación. Dykinson Centro Universitario Ramón Carande. Madrid.

SALDECO MEGALES, D. (2001): “ ¿Tiene el Estado la obligación de desarrollar una cultura de la identidad personal?" en Telos, Revista iberoamericana de estudios utilitaristas, vol. 9, nº. 1. Pág. 75-92.

SERRA ROJAS, A. (1983): Derecho administrativo: doctrina, legislación y jurisprudencia. Porrúa. México. 